\title{
Class Designing Method and Implementation for Promoting Active Learning: Four-quadrant AL Designing Method and Dynamic LMS
}

\author{
Isao Kikukawa *, Chise Aritomi *, \\ Shoichi Nakamura ${ }^{\dagger}$, Youzou Miyadera ${ }^{*}$
}

\begin{abstract}
We have proposed a "Four-quadrant AL Designing Method", a framework to design active learning classes which are in demand lately, and also have developed a new type of Learning Management System ("Dynamic LMS"). This paper gives an outline of designing active learning classes based on the Four-quadrant AL Designing Method, followed by a case study of Dynamic LMS in designed class implementation. Also class implementation and survey results conducted in 2016 academic year are reported. The survey results suggest that learning in the implemented classes was overall effective.
\end{abstract}

Keywords: Active Learning, Class Designing Method, Class Implementation, LMS

\section{Introduction}

Recently, implementation of classes accommodating "Active Learning (AL)" (hereinafter referred to as active learning classes) are in demand in educational institutions including universities [1][2]. Enriched "linkage between in-class learning and out-of-class learning" needs to be established for effective active learning classes as are shown in "flipped classroom [3]" and "flipped learning [4]". As is referred to in "self-regulated learning [5]", "learning review" also needs to be appropriately performed [6][7]. Furthermore, "learning activity development with change of roles and groups" is considered essential [8][9].

Under such circumstances, we have proposed "Four-quadrant AL Designing Method" as a framework to design active learning classes [10]. Teachers can design "activities in which in-class learning and out-of-class learning are linked" or "development of learning activity while changing roles and groups" from four viewpoints of "in-class individual activity", "in-class group activity", "out-of-class individual activity", and "out-of-class group activity" by using this method. Also we have constructed a new type of Learning Management System ("Dynamic

\footnotetext{
* Tokoha University, Shizuoka, Japan

$\dagger$ Fukushima University, Fukushima, Japan

* Tokyo Gakugei University, Tokyo, Japan
} 
LMS", hereinafter called DLMS) to effectively and efficiently support the desired learning in active learning classes [11]. In this paper, active learning classes and survey results are reported which were implemented in 2016 academic year as a trial on an extension of our previous studies. In particular, Section 2 outlines active learning class designing using Four-quadrant AL Designing Method. Section 3 describes a case study of using DLMS in designed classes. Section 4 reports class implementation and survey results held at Tokoha University in the fall term of 2016 academic year. Finally, section 5 summarizes this paper.

\section{Class Designing}

This section outlines Four-quadrant AL Designing Method (2.1), followed by class designing using this method (2.2).

\subsection{Four-quadrant AL Designing Method}

"Four-quadrant AL Designing Method" is a framework to support designing active learning classes [10], and it has been developed by expanding "Integrated Course Design Model" and "Castle Top Diagram" by Fink [1].

Table 1 shows "Integrated Course Design Model". In this model, teachers design active learning classes through Initial Phase, Intermediate Phase, and Final Phase. First, in the Steps 1 through 5, such elements as "situational factors", "learning goals", "feedback and assessment" and "teaching and learning activities", the most important ones in course designing, are analyzed and integrated (Initial Phase). Next in the Intermediate Phase based on the analysis result in the Initial Phase, course structure is constructed while major topics in the course are extracted (Step 6), "teaching strategy" for each major topic is formed (Step 7), and overall learning activity plan is determined (Step 8). After that, grading rules are determined, possible problems are predicted and prepared, course syllabus is written, and evaluation of the class is planned in the Steps 9 through 12 (Final Phase). Four-quadrant AL Designing Method is developed to improve Step 7 in particular.

Table 1: Steps in Integrated Course Design Model (Source: Fink, 2013.)

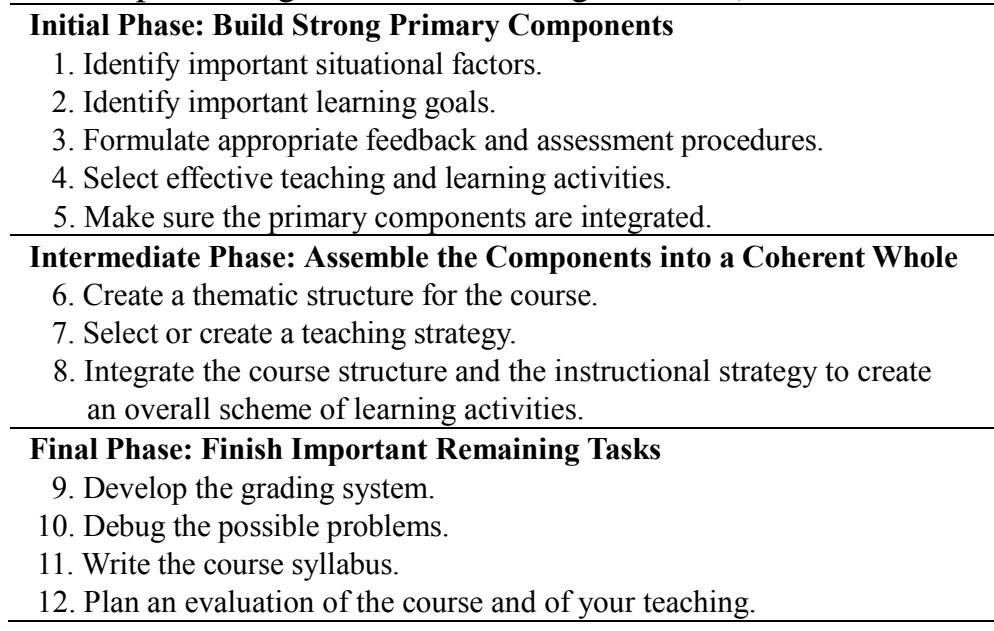

Furthermore, "Expanded Castle Top Diagram" is also developed. The original Castle Top Diagram is created to clarify "teaching strategy (combination and sequence of in-class activities 
and out-of-class activities)" while referring to learning activities that are categorized into two categories of "in-class activities" and "out-of-class activities". We expanded this diagram so that it can deal with four categories of "in-class individual activities", "in-class group activities", "out-of-class individual activities" and "out-of-class group activities". In Figure 1, the activities are divided into four-quadrant matrix so that it is easy to see which activity belongs to one of the aforementioned four categories (contents of Figure 1 can be modified according to the needs of teachers). Figure 2 shows a template of Expanded Castle Top Diagram. Teachers can clarify combination and sequence of each activity composing "teaching strategy" from the viewpoint of four-quadrant by using this diagram.

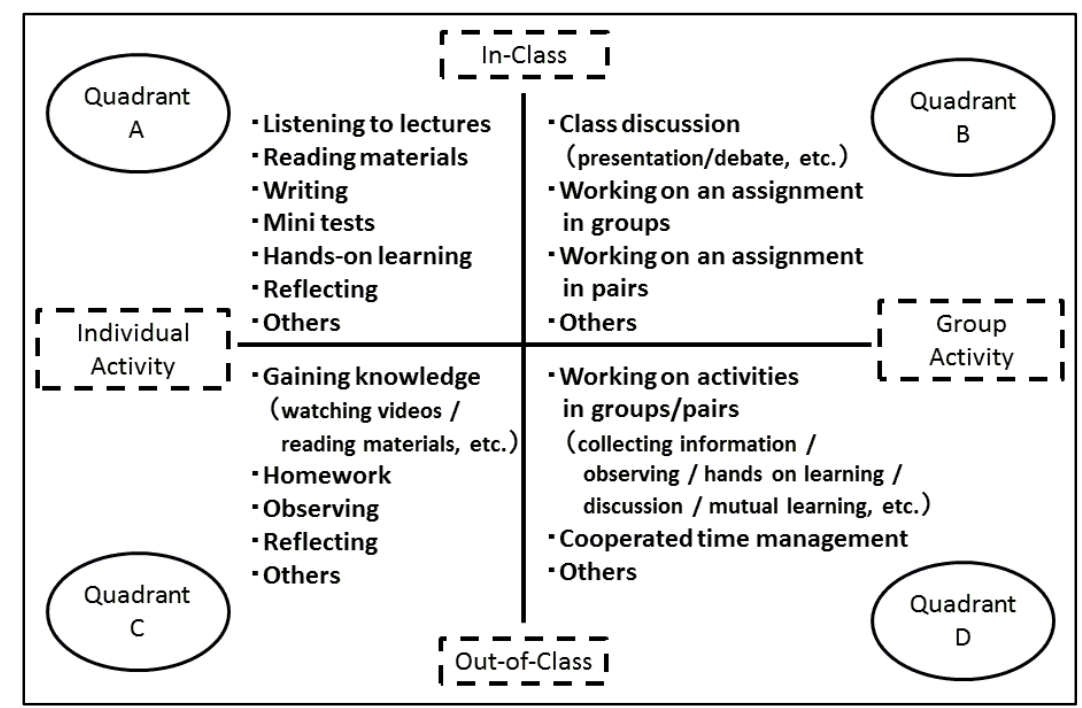

Figure 1: Four-quadrant matrix of learning activities (Source: Kikukawa, 2017.)

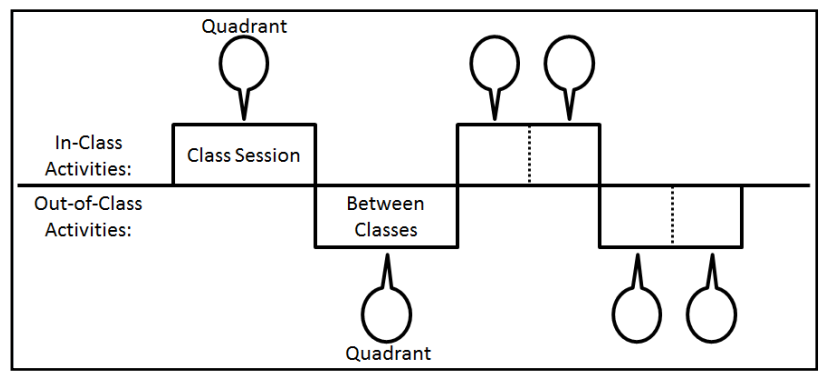

Figure 2: Template of Expanded Castle Top Diagram (Source: Kikukawa, 2017.)

Figure 3 is a process model of this designing method. In this process model, the number of class time (class session) where the Figure 2 Template is applied is examined ( 1 of Figure 3 ). After the number of class sessions is determined, designing "teaching strategy" begins ( 2 of Figure 3). In this process, combination and sequence of various activities are clarified in reference to the aforementioned learning activities (3 of Figure 3). Symbol of quadrant where a certain learning activity belongs to (one of A, B, C, or D in Figure 1) is inserted when learning activities are written in the Expanded Castle Top Diagram (4 of Figure 3). The final step is evaluating validity of the obtained Castle Top diagram ( 5 of Figure 3 ). Each teacher checks the validity of his/her diagram in accordance with the guideline in 5 of Figure 3 . In particular, such points as "are the learning activities categorized in the four-quadrant matrix included in good balance?" or "is the balance in the overview of the whole class appropriate?" are checked. If any failure is found in this checking process, Castle Top Diagram is modified through going back the steps in 
Figure 3. This work is repeated on as needed basis to complete Expanded Castle Top Diagram.

As is shown in Figure 4, we positioned the process model as a part of "Iterative Version of Integrated Course Design Model" which can flexibly accommodate "prototyping class design" and "class improvement design after class implementation" in addition to "step-by-step class design".

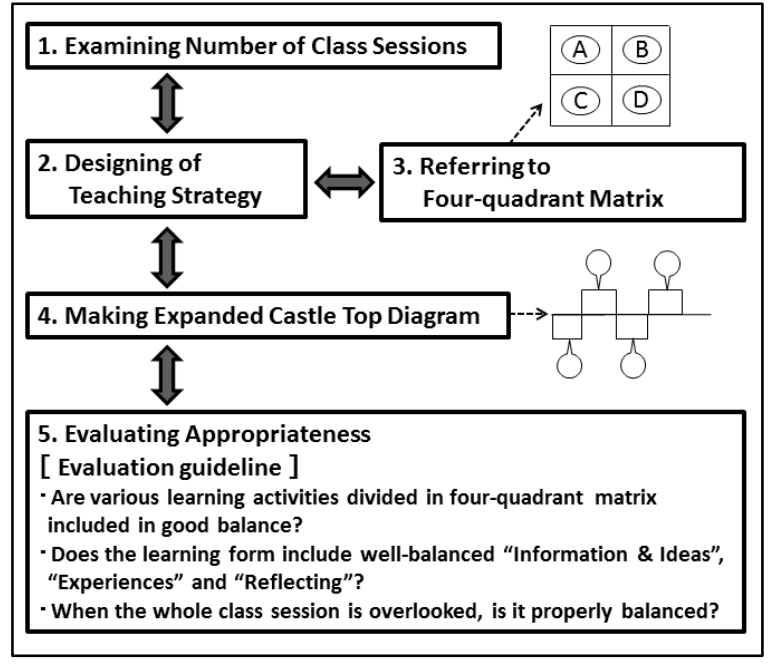

Figure 3: Process Model of Four-quadrant AL Designing Method (Source: Kikukawa, 2017.)

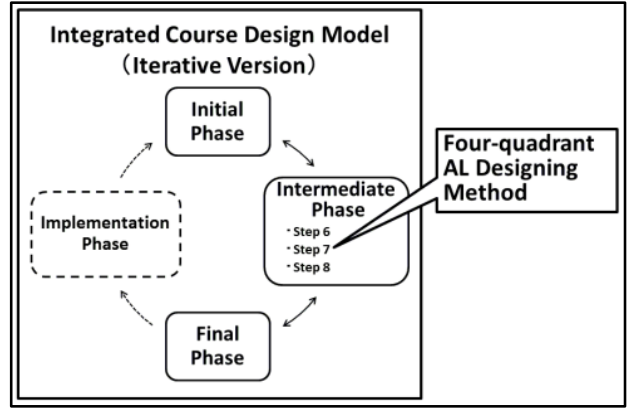

Figure 4: Image of Iterative Version of Integrated Course Design Model

(Source: Kikukawa, 2017.)

\subsection{Class Designing Using Four-quadrant AL Designing Method}

This section explains how to transform "Database (a course whose main purpose is to acquire SQL)" which one of the authors teaches into an active learning class as a sample of class designing using Four-quadrant AL Designing Method [10]. This case shows improvement from pre-transformation and serves as a sample of "class improvement designing after class implementation".

Figure 5 shows teaching strategy before transforming into active learning. Figure 5 found that pre-improvement strategy was "mainly based on activities in Quadrant A with some activities in Quadrant C".

Therefore, the policy to design new strategy was set to "cover two-week class sessions with added activities from Quadrant B and Quadrant D supplemented by activities in Quadrant C". The result is shown in Figure 6.

In the new strategy, "gaining knowledge", previously done during the class time lecture, was implemented by viewing online video contents and reference materials (preparation). During the 
class time after preparation, students worked on worksheets in groups, followed by individual actual PC operation of database. Review worksheets were prepared for homework for "between the classes". This homework took a form of problem solving in groups, similar to in-class work. During the second class time, students reported contents of group activities and learning which they have worked on between classes, and proceed to individually work on assignment of database on actual PC. Time was set at the end of each class to review the learning activities and make comments (students are occasionally instructed to review their learning and accumulate comments). When the activities in Figure 6 are checked to see where they belong to, it was confirmed that activities in all the quadrants were included in good balance.

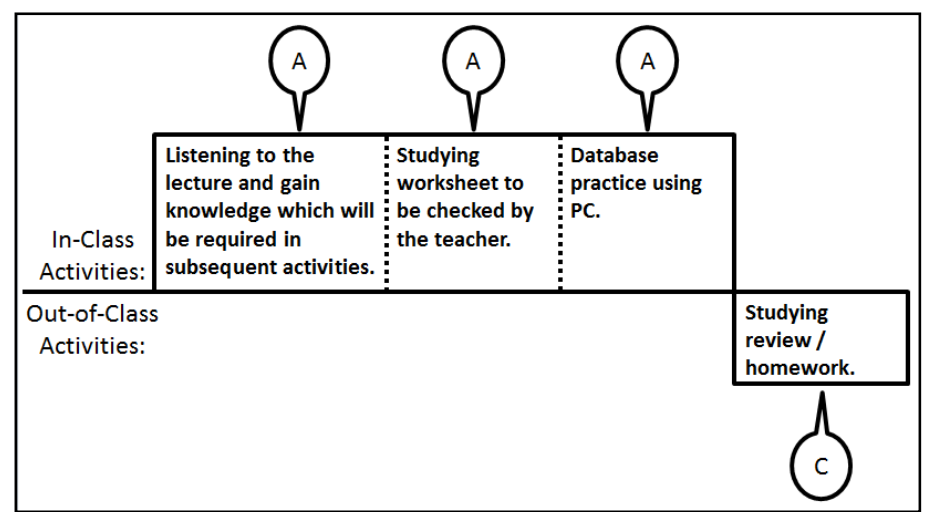

Figure 5: Teaching strategy before improvement (Source: Kikukawa, 2017.)

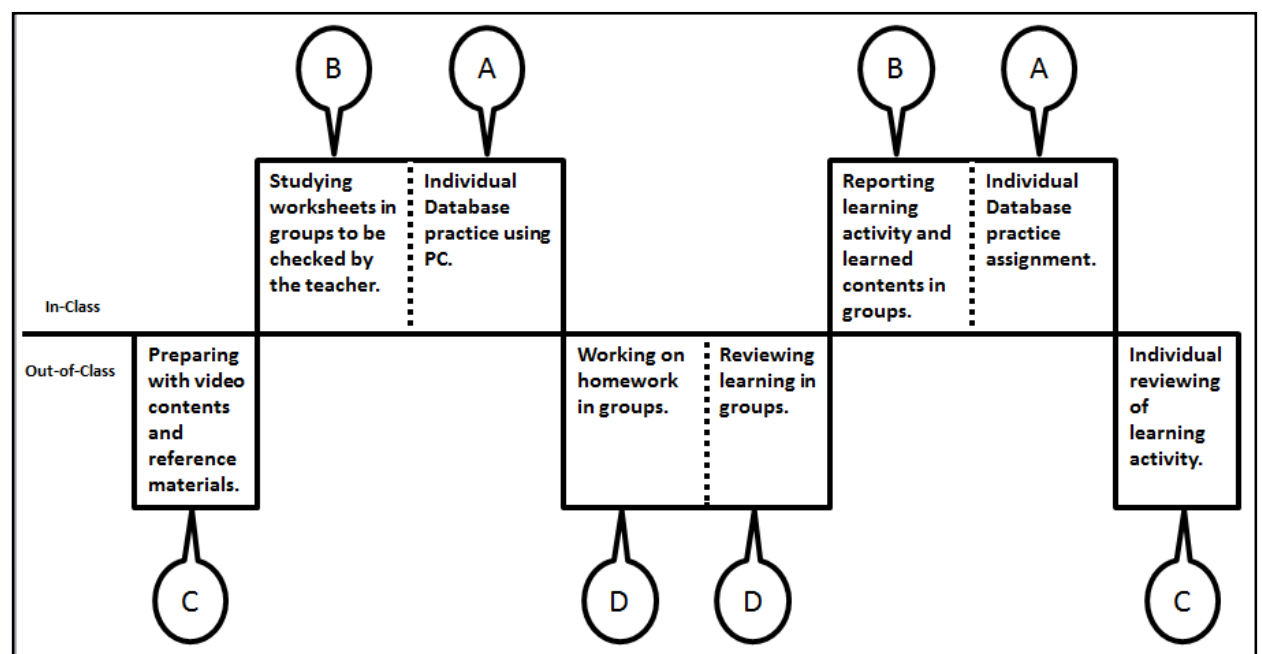

Figure 6: Teaching strategy after converting to active learning (Source: Kikukawa, 2017.)

Table 2: Class structure after converting to active learning (Source: Kikukawa, 2017.)

\begin{tabular}{cl}
\hline \multicolumn{1}{c}{ Phase } & \multicolumn{1}{c}{ Major Topics } \\
\hline 1 (3 weeks) & Introduction to database, SQL overview, etc. \\
$2(2$ weeks $)$ & INSERT statement, SELECT statement, etc. \\
$3(2$ weeks $)$ & Using WHERE clause, Sorting \\
$4(2$ weeks $)$ & UPDATE statement, DELETE statement, etc. \\
$5(2$ weeks $)$ & Joining tables (1): INNER JOIN \\
$6(2$ weeks $)$ & Joining tables (2): LEFT JOIN, RIGHT JOIN \\
$7(2$ weeks $)$ & Basics of database design \\
\hline
\end{tabular}


The whole course was examined based on thus obtained new strategy. The two class sessions included in the new strategy were considered as "phase", and learning contents and their order were reconstructed so that the whole course (total 15 sessions) consisted of 7 phases. Table 2 shows the result. Video contents and worksheets were also created to implement classes based on Table 2 and Figure 6.

In this class implementation, groups consisting of 4 to 5 students (one leader) are arranged with different group members at each phase. The students were assigned to take leadership at least once as much as possible. DLMS [11] was used to support development of leaning activities with changes in groups and roles. Use of DLMS enables students to (1) access video contents, etc., (2) communicate within his/her group, and (3) write review comments. (Detail of DLMS use is described in the next section). Because of this, Phase 1 on Table 2 describes operation of DLMS such as how to watch video contents and input comments of review. Teaching strategy shown in Figure 6 will be implemented after Phase 1.

\section{DLMS Use in Active Learning Classes}

This section starts with overview of DLMS (3.1), followed by a case study of DLMS use in "Database" class implementation.

\subsection{Overview of DLMS}

DLMS [11] was designed to expand IMS-LD [12] in order to provide learning designing environment to effectively/efficiently support learning expected in active learning classes, and was developed as Web application that works on Apache HTTP Server. Use of DLMS enables support of "learning activity development with changes in roles/groups". Figure 7 is an image of DLMS use. The scenes of DLMS use are roughly divided into edit time and run time. First, teachers make "activity progress scenario" in the edit time before class begins (Function 1). The scene moves to run time at the start of classes. Students proceed with in-class and out-of-class learning on the interface provided by DLMS during run time. Teachers can set "group and role management" according to the progress of classes (Function 2). DLMS dynamically generates/presents "interface that will be used in the next learning activity" for individual student at "punctuation of learning activity" dotted in "the series of learning activities" using progress of "activity progress scenario" and setting of "group and role management" to support in-class and out-of-class learning of students (Function 3).

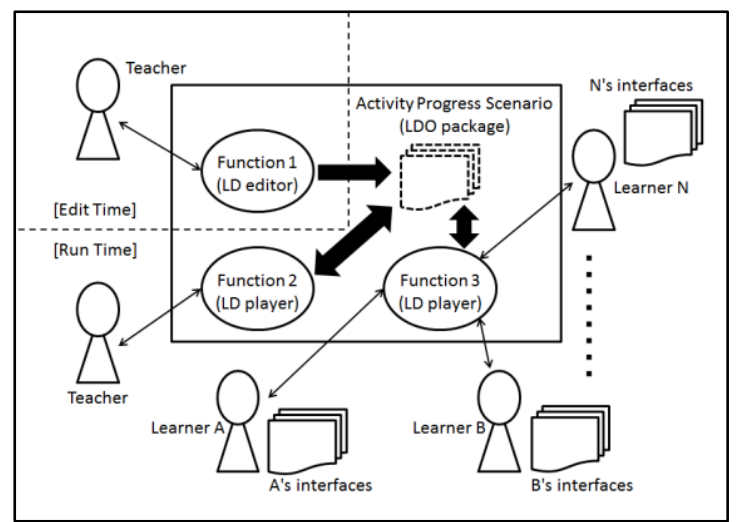

Figure 7: Image of DLMS use 


\subsection{Use of DLMS}

"Activity progress scenario" needs to be made before classes start, and there are several patterns for this. In "Database" class implementation, the aim was synergy of paralleling individual learning and group learning through using "one interface for individual learning" and "one interface for group learning" by individual student at each phase after Phase 1. An example of screenshot of "activity progress scenario" created for "Database" is shown in Figure 8-a. Students will advance individual learning and group learning (leader or member) on the DLMS after Phase 1. Also "group and role management" at each phase was available in the setting so that teachers can rearrange groups and roles (for example, leader or member) judging from class progress (Figure 8-b).
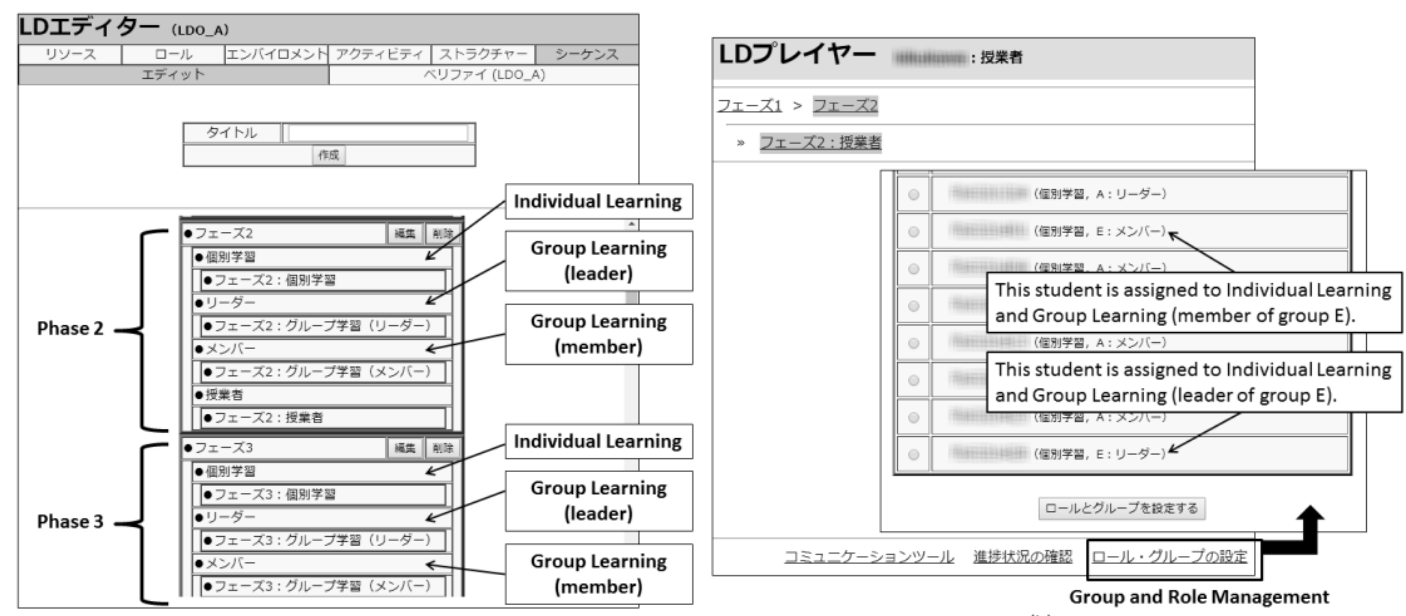

Figure 8: Screenshot of DLMS for teachers

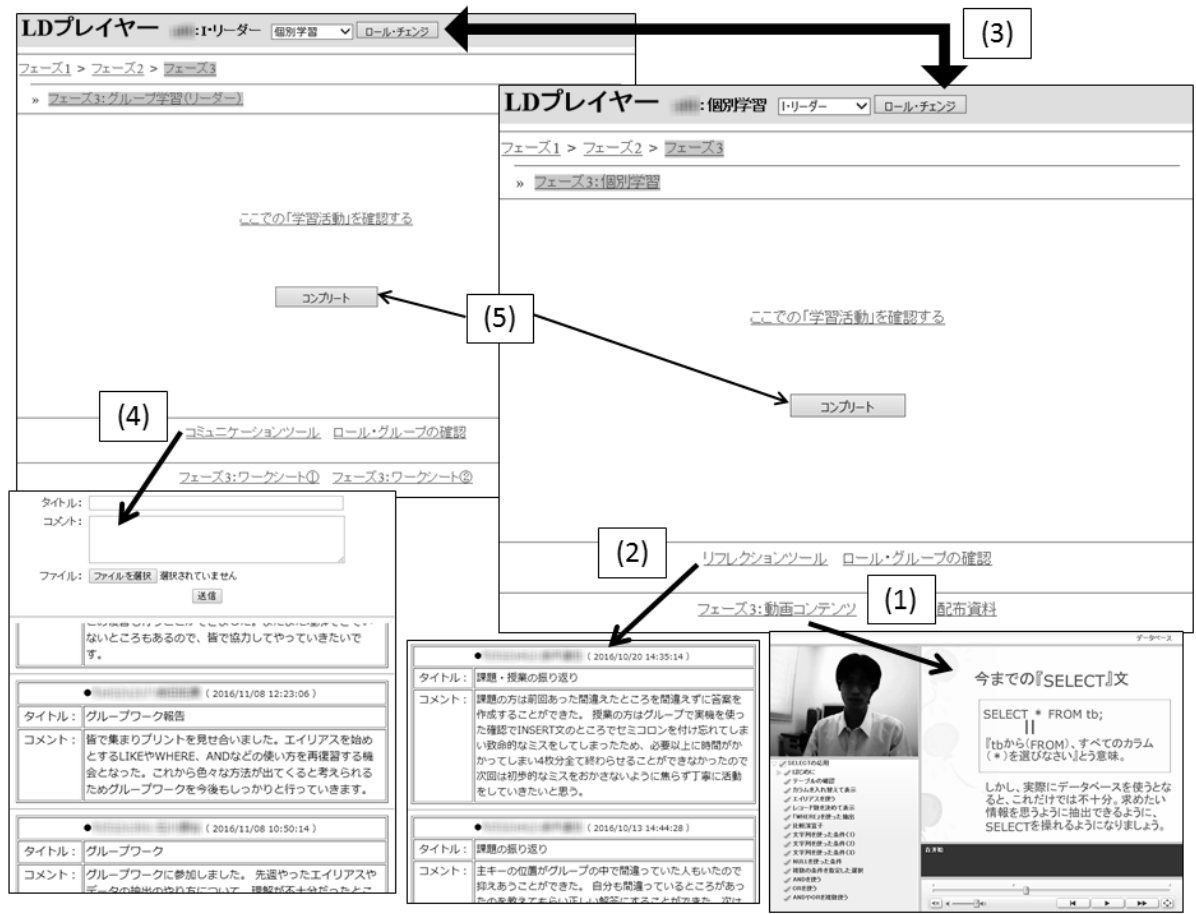

Figure 9: Screenshot of DLMS for students 
The right side of Figure 9 is "interface for individual learning". Students can grasp contents of learning activity from this screen. Also they can access video contents (1 of Figure 9) and/or record "learning review" using reflection tool (2 of Figure 9).

Clicking on "Role Change Button (3 of Figure 9)" allows switching to "interface for group learning (the left side of Figure 9)". Students can access registered learning contents and confirm group members. Also they can share information within groups using communication tool (4 of Figure 9). Furthermore, clicking on "Complete Button" in the center of both screens ( 5 of Figure 9) allows students to proceed to interface of next phase. Interface presented in the new phase is dynamically generated for each student according to the progress of "activity progress scenario" and setting of "group and role management". In this way, DLMS supports in-class and out-of-class learning for students.

\section{Class Implementation and Survey Results}

"Database" course was implemented at Fuji Campus of Tokoha University in the fall term of 2016 academic year. This course aims to acquire knowledge and skills to pass IT certification exams (for example, IT Passport Examination) by taking courses together with other courses (eg, Programming, Multimedia, Web Programming, etc.). The students in this course are more than sophomore and are those who have taken the course regardless of major. In this course, written examination (perfect score is 100) is given at the end of semesters every year, and the written exam which had the same contents as the one for 2014 academic year (before improvement) was given at the 16th class in 2016 academic year (after converting to active learning). Results of 2014 academic year (34 students) and that of 2016 academic year (26 students) are compared. The average score was 72.74 (SD: 15.99) in 2014 academic year and the average score in 2016 academic year was 81.73 (SD: 13.56). Significant difference was observed when examined with t-test (independent measures, significance level 5\%).

After the written examination, survey was conducted for the students (26 students). Table 3 is "Survey results for teaching strategy (in the scale of 1 to 5 , with 5 as the highest)", showing that most of the items earned rather high points (4 and higher). Free writing answers included such comments as "out-of-class activity made classes easier to understand", "it was nice I could review outside the class time", "thanks to group activity, we were able to solve problems that were too difficult for an individual little by little in group activity by confirming each other". These results suggested that many students acknowledge learning based on teaching strategy implemented in "Database" class highly effective. On the other hand, a few negative comments such as "I needed more practice using PC" and "I thought that it would be better to reduce the group change frequency" were also included in the free writing answers. From these comments, it was suggested that flexible correspondence to individuals in the class is more required. This is considered as a task for further improving the class.

Also most of the items (18 out of 20) in "Results of survey concerning DLMS (in the scale of 1 to 5 , with 5 as the highest)" earned high evaluation of 4 and above (Table 4). When evaluation of 4 and 5 are judged as "positive response" for DQ20 (overall evaluation for DLMS) while other responses are separated and analyzed in binominal test (two-sided), "positive response" was significant at $1 \%$ standard (number of positive response: 23 out of $26, p<.001$ ). When checked with the evaluation for DQ10 16, it was suggested that "DLMS is useful for linking in-class and out-of-class individual learning and group learning".

Overall consideration of those results reveals that learning in the implemented active learning 
classes generally turned out to be effective. Also "active learning promotion" is considered to be achieved, which was the purpose of this implementation.

Table 3: Results of survey concerning teaching strategy

\begin{tabular}{lcc}
\hline \multicolumn{1}{c}{ Questions } & M & SD \\
\hline \hline TQ1. Out-of-class "Preparation (Individual Activity)" was useful for understanding the contents of learning. & 4.00 & 0.69 \\
TQ2. In-class "Working on actual PC (Individual Activity)" was useful for understanding the contents of learning. & 4.35 & 0.56 \\
TQ3. In-class "Group Activity" was useful for understanding the contents of learning. & 4.08 & 1.02 \\
TQ4. Out-of-class "Group Activity" was useful for understanding the contents of learning. & 4.08 & 0.84 \\
TQ5. Out-of-class "Learning Review (Individual Activity)" was useful for understanding the contents of learning. & 3.85 & 0.92 \\
TQ6. I think Group Activity is necessary for enriched learning activity. & 4.12 & 0.91 \\
TQ7. I feel I could learn more contents by teaching others in Group Activity. & 4.15 & 0.92 \\
TQ8. I think the frequency of changing groups in this course was appropriate. & 4.04 & 0.92 \\
TQ9. Overall, in-class activities were useful for subsequent learning. & 3.96 & 0.92 \\
TQ10. Overall, out-of-class activities were useful for subsequent learning. & 4.19 & 0.75 \\
\hline
\end{tabular}

Table 4: Results of survey concerning DLMS

\begin{tabular}{llc}
\hline \multicolumn{1}{c}{ Questions } & M & SD \\
\hline \hline DQ1. Operation was easy. & 3.62 & 1.27 \\
DQ2. Screen structure in each page was easy to understand. & 4.00 & 0.98 \\
DQ3. Switching between multiple pages was smooth. & 4.00 & 0.94 \\
DQ4. "Role change" function was easy to use. & 3.96 & 0.92 \\
DQ5. It was easy to confirm "which role I was assigned to be". & 4.42 & 0.58 \\
DQ6. It was easy to confirm "which group I belonged to". & 4.54 & 0.71 \\
DQ7. It was easy to confirm other members in the group. & 4.31 & 0.97 \\
DQ8. It was easy to confirm "which phase I was at". & 4.35 & 0.80 \\
DQ9. I could easily grasp my own "change in learning phases". & 4.04 & 0.87 \\
DQ10. I think DLMS is useful for out-of-class preparation (Individual Learning). & 4.27 & 0.87 \\
DQ11. I think DLMS is useful for out-of-class review (Individual Learning). & 4.12 & 0.99 \\
DQ12. I think DLMS is useful for out-of-class "Group Learning". & 4.12 & 0.77 \\
DQ13. I think DLMS is useful for "Learning Review (review of learning activities)”. & 4.00 & 0.75 \\
DQ14. I think DLMS is convenient for linking in-class and out-of-class learning activities. & 4.19 & 0.75 \\
DQ15. I think we can share activities within the group. & 4.12 & 0.77 \\
DQ16. I think role change is convenient for linking individual learning and group learning. & 4.08 & 0.93 \\
DQ17. I think DLMS facilitates phase progress smoothly like this course. & 4.23 & 0.91 \\
DQ18. I think DLMS facilitates "Group Learning" smoothly like this course. & 4.35 & 0.80 \\
DQ19. I think DLMS facilitates "Learning Review" smoothly like this course. & 4.12 & 0.82 \\
DQ20. I had a good impression of DLMS overall (overall evaluation of DLMS). & 4.23 & 0.65 \\
\hline
\end{tabular}

\section{Conclusion}

We have proposed "Four-quadrant AL Designing Method", a framework to support class designing, to achieve effective active learning classes, and developed DLMS to effectively/efficiently support activities in active learning classes. This paper is based on class implementation and survey results conducted in 2016 academic year and reports results to verify va- 
lidity and usefulness of "Four-quadrant AL Designing Method" and "DLMS". Examination at the end of the term confirmed improvement of mastery, and survey results showed high level of satisfaction for "teaching strategy" and "DLMS". However, this result comes from implementation of one course. The issue is to collect application case studies in more classes. Therefore we intend to ask other teachers to apply this designing method and DLMS in their classes for more detailed evaluation through survey results.

\section{References}

[1] L.D. Fink, Creating Significant Learning Experiences: An Integrated Approach to Designing College Courses, John Wiley \& Sons, 2013.

[2] R.B. Barr and J. Tagg, "From Teaching to Learning - A New Paradigm for Undergraduate Education," Change: The magazine of higher learning, 27(6), 1995, pp. 12-26.

[3] J. Bergmann and A. Sams, Flip Your Classroom: Reach Every Student in Every Class Every Day, International Society for Technology in Education, 2012.

[4] J. Bergmann and A. Sams, Flipped Learning: Gateway to Student Engagement, International Society for Technology in Education, 2014.

[5] B.J. Zimmerman, S. Bonner, and R. Kovach, Developing Self-regulated Learners: Beyond Achievement to Self-efficacy, American Psychological Association, 1996.

[6] L. Nilson, Creating Self-regulated Learners: Strategies to Strengthen Students? Self-awareness and Learning Skills, Stylus Publishing, LLC, 2013.

[7] S.A. Ambrose, M.W. Bridges, M. DiPietro, M.C. Lovett, and M.K Norman, How Learning Works: Seven Research-based Principles for Smart Teaching, John Wiley \& Sons, 2010.

[8] E.F. Barkley, K.P. Cross, and C.H. Major, Collaborative Learning Techniques: A Handbook for College Faculty. John Wiley \& Sons, 2014.

[9] D.W. Johnson, R.T. Johnson, and E.J. Holubec, Circles of Learning: Cooperation in Classroom, Edina, MN: Interaction Book Company, 5, 1990.

[10] I. Kikukawa, C. Aritomi, S. Nakamura, and Y. Miyadera, "Developing a Framework to Support Designing of Active Learning Class", Software Engineering, Artificial Intelligence, Networking and Parallel/Distributed Computing, Studies in Computational Intelligence (SCI), Springer, Vol. 721, 2017, pp. 137-149.

[11] I. Kikukawa, C. Aritomi, and Y. Miyadera, "Development of a LMS with Dynamic Support Functions for Active Learning", Computer and Information Science, Studies in Computational Intelligence (SCI), Springer, Vol. 656, 2016, pp. 103-117.

[12] IMS Global Learning Consortium, Learning Design Specification, http://www.imsglobal.org/learningdesign/index.html. 